\title{
Discriminating Vital Tumor from Necrotic Tissue in Human Glioblastoma Tissue Samples by Raman Spectroscopy
}

\author{
Senada Koljenović, Lin-P'ing Choo-Smith, Tom C. Bakker Schut, Johan M. Kros, \\ Herbert J. van den Berge, and Gerwin J. Puppels \\ Department of General Surgery 10M (SK, L-PC-S, TCBS, GJP), Laboratory for Intensive Care Research and Optical \\ Spectroscopy, Department of Pathology (JMK), and Department of Neurosurgery (JHvdB), Erasmus University \\ Rotterdam and University Hospital Rotterdam 'Dijkzigt,' Rotterdam, The Netherlands
}

\begin{abstract}
SUMMARY: Vital and necrotic glioblastoma tissues were studied by Raman microspectroscopy to identify possibilities for the development of an in vivo Raman method for real-time intraoperative brain biopsy guidance. The histologic malignancy grade of gliomas depends on the presence of parameters such as endothelial proliferation and necrosis, which are often not evenly distributed within the tumor. Because tissue samples obtained by stereotactic surgery are relatively small, sampling errors may easily occur by missing these crucial features. Although necrosis is important for grading, specimens containing only necrosis are diagnostically useless. Raman microspectroscopic mapping experiments were performed on unfixed cryosections of glioblastoma, obtained from 20 patients. After spectral acquisition, a clustering analysis was performed, resulting in groups of similar spectra. Each cluster was assigned a color, and pseudo-color Raman maps of the tissue sections were constructed. After the Raman experiments, the tissue sections were stained for histopathologic analysis, enabling identification of the histologic origin of the Raman spectra and assignment of the Raman spectral clusters to either vital or necrotic tissue. A classification model for discrimination between vital and necrotic tumor tissue based on linear discriminant analysis was developed. The classification model was evaluated using independent Raman data obtained from nine other tissue sections and yielded $100 \%$ accuracy. Information about the biochemical differences between necrosis and vital tumor was obtained by the analysis of difference spectra. Necrotic tissue was found to consistently contain higher levels of cholesterol (-esters). This in vitro result indicates that Raman spectra contain the information to distinguish vital glioblastoma from necrosis and makes Raman spectroscopy a powerful candidate for guidance of stereotactic brain biopsy. (Lab Invest 2002, 82:1265-1277).
\end{abstract}

$T$ he most common group of primary brain tumors are the gliomas, consisting largely of tumors of astrocytic or oligodendroglial lineage. These tumors are graded according to histopathologic characteristics, and tumors of the highest malignancy grade are called glioblastomas. Within the glioma group, the glioblastomas occur most frequently (Kleihues, 2000). Tumor tissue samples are mainly obtained by stereotactic surgery. This procedure is particularly suitable for taking biopsy specimens from parts of the brain that are not otherwise accessible. An obvious disadvantage of stereotactic surgery is the fact that the specimens are relatively small (Glantz et al, 1991; Kros, 1997; Sawin et al, 1998). The designation of a malignancy grade to gliomas occurs according to the presence of histologic parameters such as endothelial proliferation and necrosis, which are often not evenly distributed throughout the sample (Bullard et al, 1986; Hildebrand et al, 1997; Kleihues, 2000). Sampling

DOI: 10.1097/01.LAB.0000032545.96931.B8

Received February 11, 2002.

Address reprint requests to: Dr. G. J. Puppels, University Hospital Rotterdam "Dijkzigt," Surgery 10M, Dr. Molewaterplein 40, 3015 GD Rotterdam, The Netherlands.E-mail: Puppels@heel.fgg.eur.nl errors obviously will result in the underestimation of the malignancy grade of the gliomas. Further, despite the fact that necrosis is important for grading, a diagnosis cannot be made when only necrotic tissue is present in the sample (Glantz et al, 1991). In some cases the tumor component consisting of necrosis may comprise more than $80 \%$ of the total volume (Kleihues, 2000).

Although the stereotactic biopsy procedure is generally supported by computed tomography or magnetic resonance imaging guidance, these techniques only provide limited clues as to the histologic composition of the tumor. Hence, there is a need for guidance during the stereotactic biopsy procedure. Such tools will result in higher quality tissue specimens for histopathologic evaluation. In recent studies watersuppressed ${ }^{1} \mathrm{H}$ magnetic resonance spectroscopy (MRS) has been put forward as a noninvasive way for detecting significant differences between the in vivo spectra of tumor, necrosis, and healthy brain tissue (Dowling et al, 2001; Fountas et al, 2000; Hall et al, 1999; Kurhanewicz et al, 2000; Nelson et al, 1999; Pirzkall et al, 2001; Vigneron et al, 2001) and for targeting during brain biopsy (Hall et al, 2001). In the latter study, all biopsy material obtained under MRS 
guidance was reported to be useful for diagnosis. MRS adds valuable information to intraoperative MR imaging. However, the cost and size of the instruments may hamper the widespread use of MRS.

In the study reported here, we have investigated the possibility of using Raman spectroscopy to distinguish between vital tumor tissue and necrosis to identify possibilities for the development of an in vivo Raman method as the basis for intraoperative brain biopsy guidance. Raman spectroscopy is a nondestructive vibrational spectroscopic technique, based on inelastic scattering of light by the molecules in a sample. A Raman spectrum provides information about the molecular composition, molecular structures, and molecular interactions in a tissue (Tu, 1982). Different types of tissue will vary in their overall molecular composition. Therefore their Raman spectra will also be different and can be used as tissuespecific spectroscopic fingerprints. In addition, pathologic changes in molecular composition or structure are reflected in the spectra, enabling development of diagnostic tools based on Raman spectroscopy. In recent years, significant progress has been reported in the application of Raman spectroscopy for ex vivo and in vivo tissue characterization (Bakker Schut et al, 2000; Boustany et al, 1999; Buschman et al, 2000; Frank et al, 1995; Hanlon et al, 2000; MahadevanJansen and Richards-Kortum, 1996; MahadevanJansen et al, 1998a, 1998b; Manoharan et al, 1994, 1996, 1998; Shim et al, 2000; Stone et al, 2000; Wolthuis et al, 1999). So far only a few studies have reported on the use of Raman spectroscopy for brain tissue characterization. Mizuno et al (1994) analyzed Raman spectra of different anatomical and functional structures of rat brain. Ong et al (1998) showed that Raman spectroscopy can be used to identify the substantia nigra of monkey brain. Recently we showed that Raman spectroscopy can be used to accurately determine water concentration in brain tissue (Wolthuis et al, 2001). In 1994, Mizuno et al (1992) were the first to publish spectra of different brain tumors.

Here we used Raman microspectroscopy to obtain spectra of unfixed thin sections of human glioblastoma tissue samples. The thin sections were scanned to create pseudo-color Raman maps, which were compared with the histopathology of the same tissue sections. We were able to identify the histologic origin of the spectral features that were collected. A classification model was then developed that distinguishes between vital tumor tissue and necrosis based on the Raman spectra of the tissue under investigation. An independent data set was used to evaluate the model.

\section{Results}

Twenty-four Raman mapping experiments were performed on unstained, unfixed cryosections of 20 glioblastoma tissue samples taken from 20 patients. The maps varied in size from 200 pixels (in a few cases, in which small structures within a section were mapped at high resolution) to 13,000 pixels (for larger areas in tissue sections, containing both vital and necrotic tissue). Regions within the unstained tissue sections containing vital tumor tissue and necrotic tissue were identified by histopathologic evaluation of a hematoxylin and eosin (HE)-stained adjacent tissue section and selected for Raman scanning. Bright-field microscopic images of such regions in unstained sections are shown in Figure 1 (A and B). After Raman spectral acquisition, the data were analyzed by principal component (PC) analysis (PCA) and K-means cluster analysis (KCA). Each cluster (consisting of similar spectra) was assigned a color. Pseudo-color Raman maps were then created in which the color of each pixel is determined by the cluster membership of the spectrum obtained from that pixel. Representative examples of Raman pseudo-color maps are shown in Figure 1 ( $C$ and $D)$. Because in KCA the user determines the number of clusters, a protocol was adopted in which for each tissue section, several KCA were carried out with an increasing number of clusters, as long as this resulted in clusters containing biochemical information (see "Materials and Methods"). This ensured that the resulting clusters captured all essential signal variance. In this way KCA of the spectra obtained from the first 11 glioblastoma samples resulted in a total of 72 clusters (the number of clusters per sample ranging from 4 to 11). After the acquisition of the Raman spectra, the tissue sections were $\mathrm{HE}$ stained (Fig. 1, E and F). This enabled a histologic evaluation of the different clusters in the Raman maps, which showed that Raman clusters correspond to either necrotic areas (the weaker stained areas, marked " $n$ " in Fig. 1, E and F) or vital tumor areas (the more intensely stained areas, marked " $v$ "). A large number of clusters imply that significant biochemical variation is present within necrotic tissue areas and within vital tissue. A clear illustration of this is given by Figure 1 ( $D$ and $F)$, which shows a large necrotic region surrounded by an area of closely packed cells referred to as pseudopalisading (marked " $p$ "). In between the palisading cells, numerous disintegrating (necrotic) cells are also present, as shown in Figure 1G (arrows). In the pseudo-color maps $1 \mathrm{C}$ and 1D, shades of red were used to locate areas (and variance in biochemical composition) of vital tumor tissue. Likewise, shades of blue were used for necrosis. Figure 2 shows representative spectra of different areas of vital tumor tissue (spectra A, B, and C), which serve to illustrate the spectral variance encountered in vital tumor tissue. The difference spectrum 2D (2A minus 2C) shows clear overlap with Raman spectra of pure glycogen (2E and open bars) and fatty acids ( $2 \mathrm{~F}$ and gray bars). Similarly, representative spectra (spectra A, B, and C) of necrotic areas are shown in Figure 3 . The difference spectrum ( $3 \mathrm{~A}$ minus $3 \mathrm{C}$ ) is shown in Figure $3 \mathrm{D}$, and spectral regions of most prominent signal contributions from cholesterol (3E and open bars) and calcium hydroxyapatite (3F and gray bars) are highlighted. Based on the histopathologic evaluation, a total of 36 clusters were labeled as "necrotic" and 36 as "vital." For each cluster a cluster-averaged spectrum was calculated and used to develop a linear discriminant 

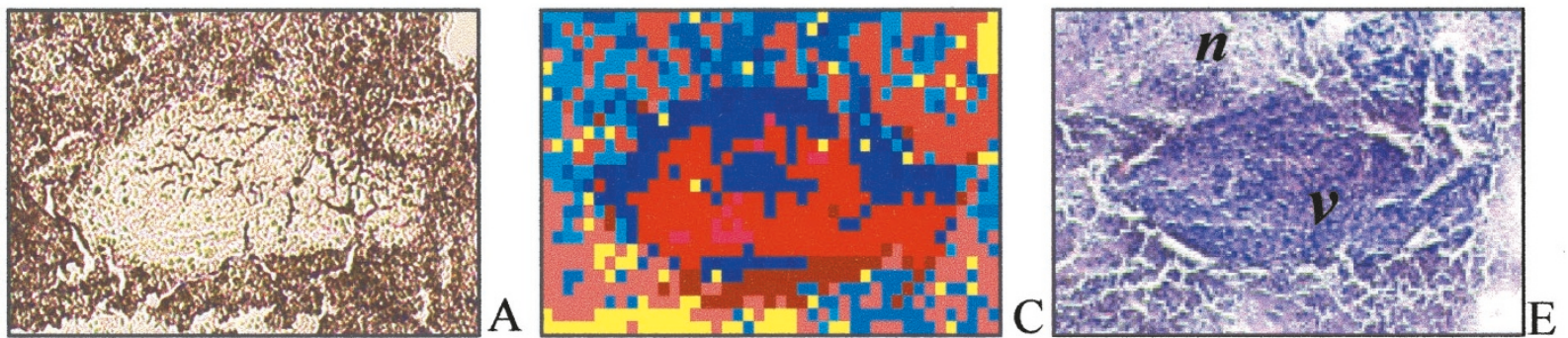

(Size: $860 \times 500 \mu \mathrm{m}$ )
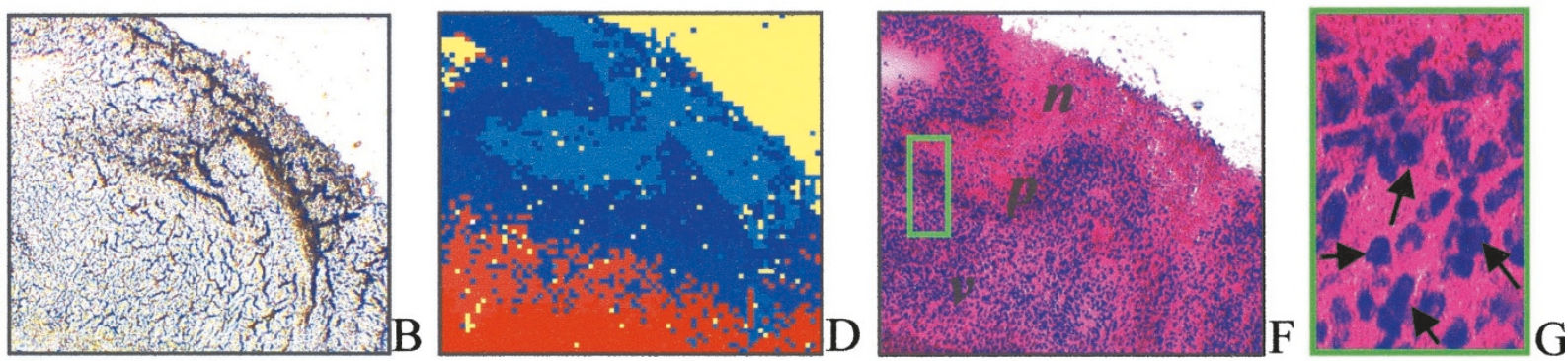

(Size: $888 \times 828 \mu \mathrm{m}$ )

\section{Figure 1.}

$A$ and $B$, Photomicrographs (original magnification, $\times 5$ ) of unstained $(25 \mu \mathrm{m}$ thick) human glioblastoma cryosections used in Raman mapping experiments. $C$ and D, Pseudo-color Raman maps based on the K-means cluster analysis (KCA) of Raman spectra of the tissue sections shown in A and B. Red: areas of vital tumor tissue; blue: areas of necrosis (see text); yellow: areas in the scan where no tissue was present (edges, freezing artifacts). E and F, Photomicrographs (original magnification, $\times 5$ ) of the same tissue sections, after $\mathrm{HE}$ staining for histologic evaluation following Raman measurements (vital tissue designated with $v$ and necrotic with $n$ ). Typical necrosis surrounded by pseudopalisading tumor cells is present in $\mathrm{F}$ (marked with $p$ ). $\mathrm{G}, \times 40$ magnification of detail marked with a green frame in $\mathrm{F}$; in between the pseudopalisading cells, disintegrating tumor cells are visible (arrows).

analysis (LDA) model for discrimination between necrosis and vital tumor tissue (see "Materials and Methods"). PCA was applied to obtain a reduced number of orthogonal variables for this LDA model data set.

The significance of each PC in discriminating between the two tissue classes (vital versus necrotic glioblastoma tissue) was calculated using a two-sided $t$ test. These values are listed in Table 1. As can be seen, the two PCs that exhibit the highest significance are PC 2 and PC 22. The scores of the clusteraveraged spectra on these two PCs are shown in Figure 4. The figure clearly shows that the two groups of tissue spectra can be separated using only PC 2 and that PC 22 does not add significant discriminatory information.

To minimize the risk of overfitting the data on which the LDA model was developed, only the scores on PC 2 were used as input for the model. This PC represents $17.44 \%$ of the total signal variance present in the data set. A leave-one-out cross-validation of this LDA model resulted in an accuracy of $100 \%$.

The LDA model was tested using an independent data set collected from the next 13 Raman mapping experiments (on tissue sections of 9 patients who were not included in the model training set). KCA was performed in the same way as for the model data set, resulting in a total of 70 clusters. Pseudo-color maps were again compared with histopathology. This resulted in 42 clusters being labeled "vital" and 28 "necrotic." Cluster-averaged spectra were calculated for all clusters, and the LDA model was then used to predict whether these spectra were obtained of vital or necrotic tissue. The results were compared with histopathologic classification. A $100 \%$ correspondence was found.

To visualize the distribution of vital and necrotic tissue as predicted by the LDA model, Raman prediction maps were generated by applying the LDA model to each individual spectrum (pixel) of the map. Examples of prediction maps are shown in Figure 5 (C and D). A comparison with the histopathologic evaluation of the HE-stained sections (5E and 5F) serves to illustrate the accuracy of the LDA model.

Raman spectra of necrotic and viable glioblastoma (which are averaged over all necrotic clusters and all vital clusters, respectively, in the LDA model set) are shown in Figure 6 (spectra A and B). A difference spectrum (necrosis minus vital tumor) is displayed in $6 \mathrm{C}$. It closely resembles spectra of pure cholesterol and cholesterol esters such as cholesterol oleate and cholesterol linoleate (spectra D, E, and F, respectively). The presence of esters in the necrotic glioblastoma tissue can be deduced from the characteristic band at $1739 \mathrm{~cm}^{-1}$, barely visible in Figure $6 \mathrm{~A}$ but clearly present in the difference spectrum (Fig. 6C). Other readily interpretable differences are visible near 1300 $\mathrm{cm}^{-1}$ (assigned to $\mathrm{CH}_{2}$ twist and wagging vibrations), $1131 \mathrm{~cm}^{-1}$ (C-C stretching), $1086 \mathrm{~cm}^{-1}$ (C-C stretching and $\mathrm{PO}_{2}^{-}$symmetric stretching), and $1063 \mathrm{~cm}^{-1}$ (C-O stretching and C-O-C symmetric stretching) (Mizuno et al, 1994; Tu, 1982). These bands are 


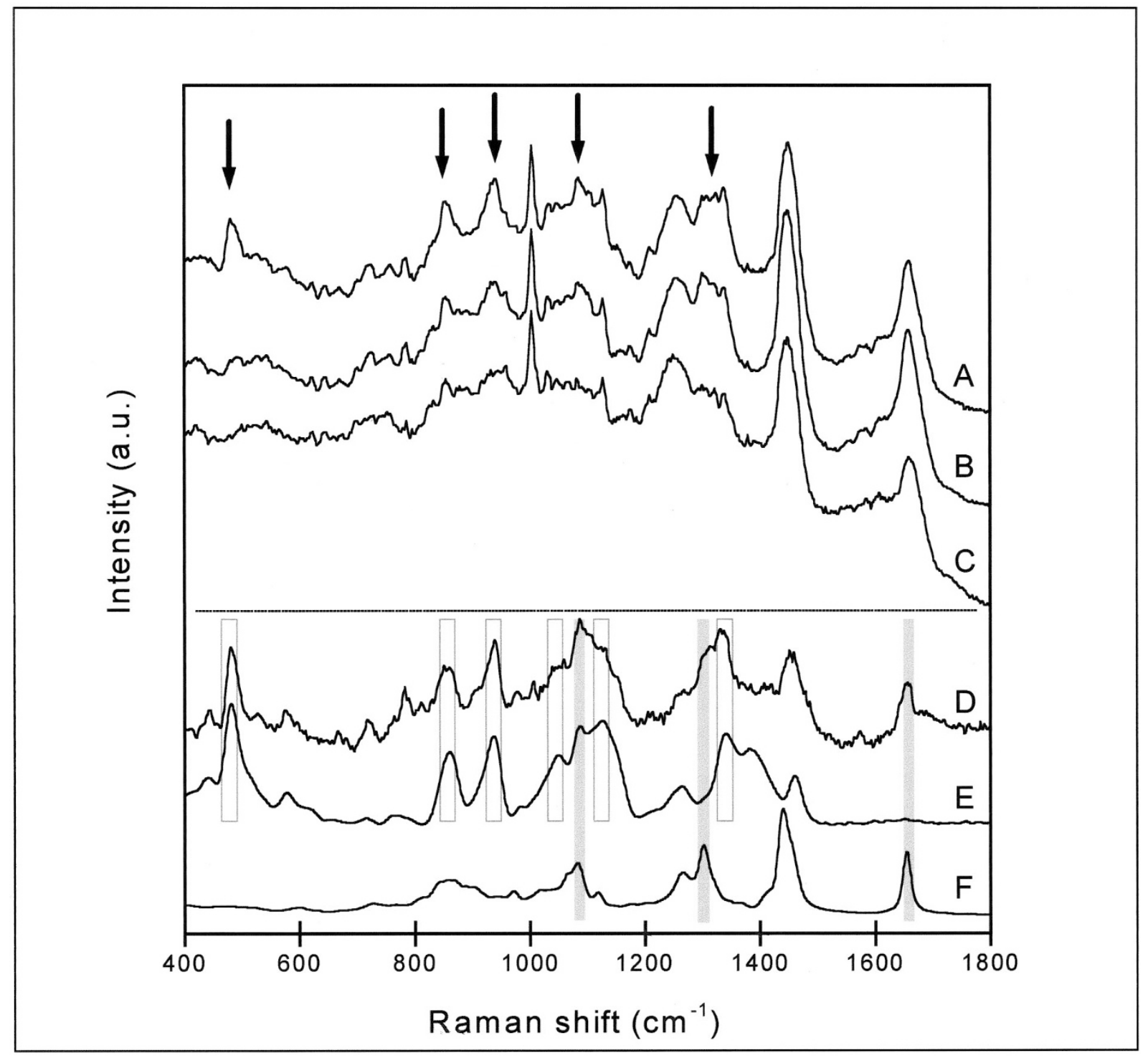

Figure 2.

A to C, Representative cluster-averaged Raman spectra collected from vital glioblastoma. These spectra are representative of the signal variance encountered within vital tumor areas of the tissue section shown in Figure 1. Arrows indicate spectral regions with clear signal variance (a.u. = arbitrary units); D, Difference spectrum 2A minus 2C; E, Raman spectrum of pure glycogen; F, Raman spectrum of fatty acid (oleic acid). Open bars (glycogen) and gray bars (fatty acid) have been used to highlight areas of significant spectral overlap between these compounds and the difference spectrum 2D.

assigned to fatty acids and phospholipids. The difference spectrum also shows small features at 1523 and $1159 \mathrm{~cm}^{-1}$, which resemble carotenoids, and an intense band at $958 \mathrm{~cm}^{-1}$ probably caused by calcifications (Mizuno et al, 1994).

Crystal-like inclusions were frequently observed in necrotic regions during standard microscopic examination of unstained tissue. An example of such an inclusion is shown in Figure 7. The strong spectral overlap between spectrum (Fig. 7C) of the inclusion and pure cholesterol spectrum (see Fig. 3E) shows that the crystal consists mainly of cholesterol. The presence (and amount) of crystals within necrotic parts of the tumor correlated with the extent of tumor necrosis as it was histopathologically assessed. Furthermore, in necrotic tumor regions in frozen sections from five patients, calcification deposits were ob- served. An example of such a calcification deposit is shown in photomicrograph 8A. The KCA Raman map is shown in Figure 8B. Spectra $a$ and b in Figure $8 \mathrm{C}$ show cluster-averaged spectra from the surrounding necrotic tissue (" $a$ ") and from the periphery (" $b$ ") of the deposit, respectively (see Fig. 8B). Spectrum c (cluster average), which was obtained from the center of the inclusion ("c"), shows a very high signal contribution of calcium hydroxyapatite (see Fig. 3F).

In six tissue sections from four patients, the Raman spectra obtained from vital glioblastoma indicated the presence of regions with very high glycogen concentrations. A representative spectrum is shown in Figure 9A (see a spectrum of pure glycogen in Fig. 2E). A bright-field image and the KCA Raman map are displayed in Figure 9, B and C, respectively. 


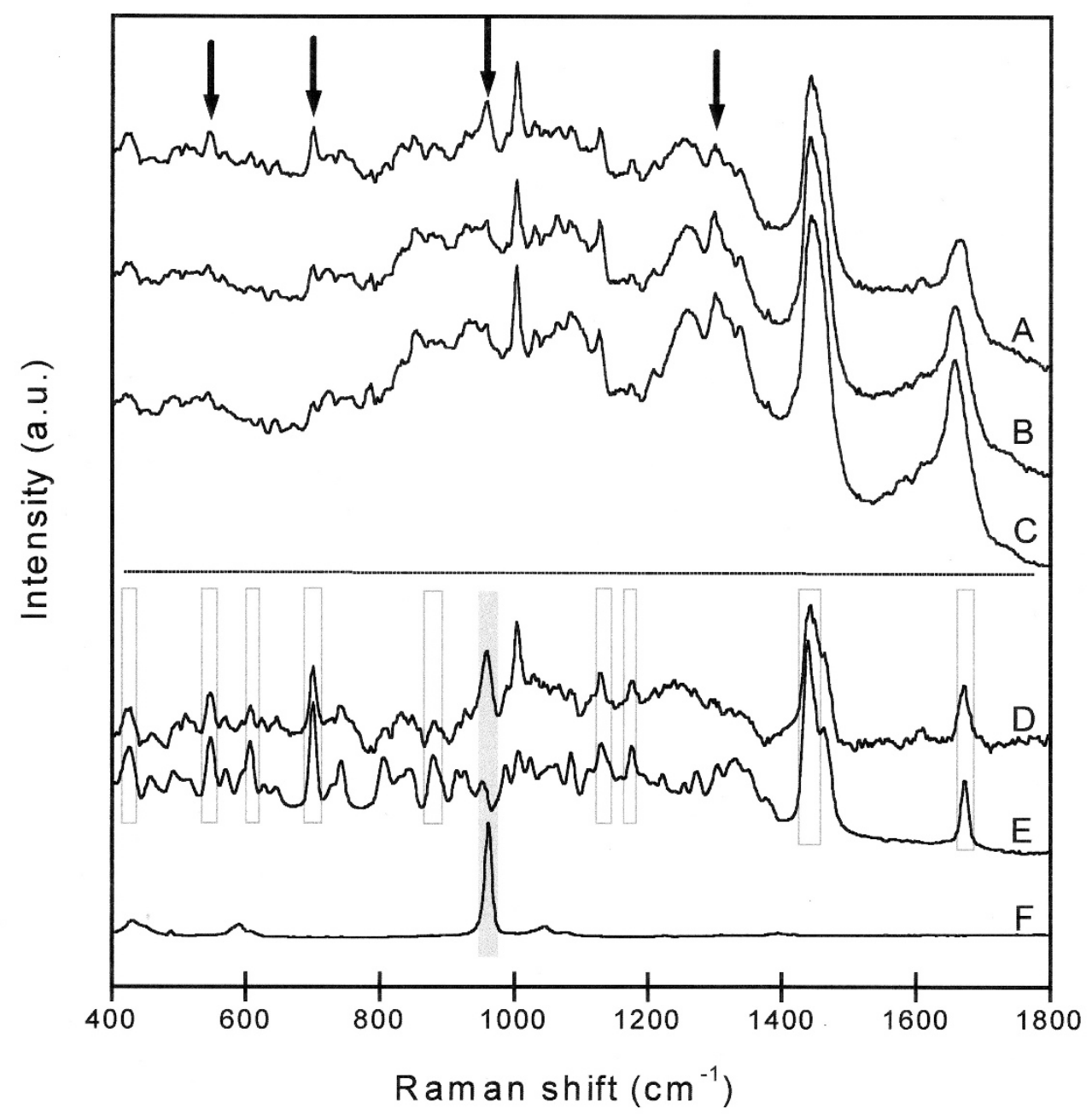

Figure 3.

A to C, Raman spectra obtained from different necrotic parts within the tissue section shown in Figure 1. Spectral regions with clear signal variance are marked with arrows (a.u. = arbitrary units); D, Difference spectrum 3A minus 3C; E, Raman spectrum of pure cholesterol; F, Raman spectrum of calcium hydroxyapatite. The regions of most striking resemblance between difference spectrum (3D) and spectra of pure cholesterol (3E, open bars) and calcium hydroxyapatite (3F, gray bars) are highlighted.

\section{Discussion}

The results of this study show that the biochemical information represented in Raman spectra distinguishes necrotic tissue from viable glioma tissue. The LDA prediction model that was developed for this purpose, in this in vitro study with nonetheless a relatively low number of samples, had a $100 \%$ accuracy. This paves the way for the development of an in vivo Raman spectroscopic method for improving intraoperative, real-time brain biopsy guidance. This is important because it will enable the collection of more representative tissue material at stereotactic biopsy than is presently possible, thereby improving the classification and grading of glioma (Bullard et al, 1986; Glantz et al, 1991; Kleihues et al, 1984; Paulus and Peiffer, 1989; Scerrati and Rossi 1984). Specimens consisting entirely of necrotic tumor tissue are diag- nostically useless. However, in the context of a neoplastic glial proliferation, necrosis is a significant histologic feature for classification and grading. Consequently, biopsy target selection by Raman spectroscopy may substantially influence histopathologic diagnosis, which is essential for treatment selection and prognosis of gliomas. Although complications after a stereotactic brain biopsy procedure are infrequent, the procedure is not entirely without risk (eg, hemorrhage or direct trauma) for the patient (Field et al, 2001). Raman-guided biopsy will decrease the number of cases in which a second stereotactic biopsy procedure is needed when no representative tumor tissue is obtained the first time.

The utility of intraoperative MRS for targeting during brain biopsy has been reported recently (Hall et al, 2001). Raman spectroscopy, like MRS, provides bio- 
Table 1. Significance of the First 22 Principal Components for Discrimination Between Vital and Necrotic Glioblastoma Tissue as Determined by a Two-Sided $t$ Test

\begin{tabular}{cc}
\hline PC number & Significance \\
\hline 1 & 0.79 \\
2 & 1.00 \\
3 & 0.78 \\
4 & 0.62 \\
5 & 0.55 \\
6 & 0.62 \\
7 & 0.82 \\
8 & 0.55 \\
9 & 0.69 \\
10 & 0.72 \\
11 & 0.50 \\
12 & 0.52 \\
13 & 0.79 \\
14 & 0.67 \\
15 & 0.65 \\
16 & 0.62 \\
17 & 0.53 \\
18 & 0.58 \\
19 & 0.87 \\
20 & 0.52 \\
21 & 0.62 \\
22 & 0.91 \\
\hline
\end{tabular}

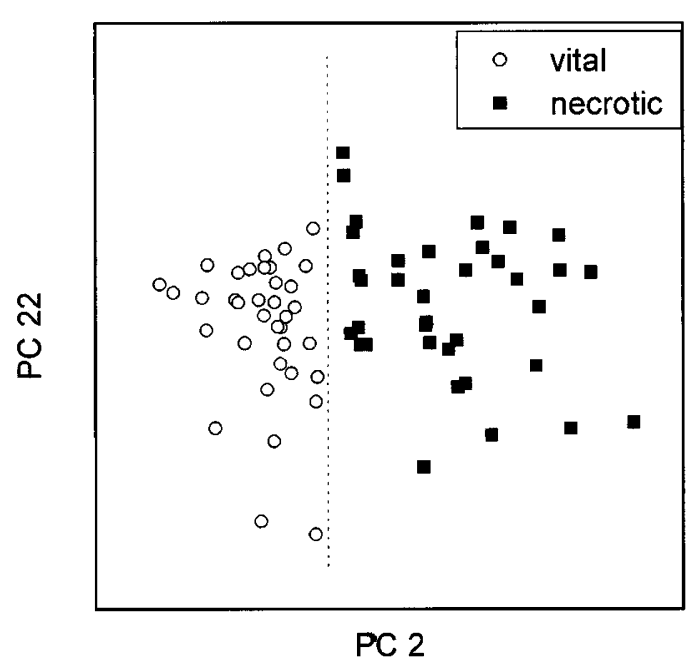

Figure 4.

Score plot of the cluster-averaged spectra on the two most significant principal components (PCs), PC 2 and PC 22. The figure clearly shows that the two groups of tissue spectra (vital vs necrotic glioblastoma) can be separated using only PC 2 and that PC 22 does not add significant discriminatory information.

chemical information about different tissues, but may be more suitable for routine use because it is faster, less complicated, and relatively low cost. Thus, the combination of Raman spectroscopy with stereotactic biopsy in addition to existing preoperative imaging techniques (computed tomography) is particularly attractive.
By correlating Raman spectral maps with histopathology of the same tissue sections, we were able to identify the morphologic origin that gave rise to the specific spectral features found in this study. Different parts of the tumor had characteristic Raman spectra, enabling the discrimination of vital and necrotic tumor. One of the most pronounced differences separating the spectra of necrotic glioblastoma regions from viable tumor is the increased signal contribution of cholesterol and cholesterol esters in necrotic tissue (Fig. 5). Increased levels of cholesterol esters (particularly cholesterol oleate and cholesterol linoleate) in glioma tissue have been reported before (Campanella, 1992; Gopel et al, 1963; Nygren et al, 1997). In these studies necrotic and vital tumor regions were not separately investigated, and therefore, no specific information regarding the biochemical composition of these distinct tumor regions was obtained. Previous results from studies on brain tumors using proton MRS (Barba et al, 1999; Negendank et al, 1996; Rémy et al, 1997) also provided evidence of mobile lipid resonances (resonances arising from fatty acyl chains of lipids), possibly caused by cell proliferation arrest and necrosis. These findings were confirmed by other MRS studies in which the morphologic and biochemical features were compared (Kuesel et al, 1994a, 1994b, 1996). Furthermore, a study of phenotypic changes occurring in rat cell cultures that were conditionally transformed by an activated $\mathrm{H}$-ras oncogene suggested that cellular growth inhibition is accompanied with massive accumulation of neutral lipids, mostly cholesterol esters and triglycerides (Hirakawa et al, 1991).

The biochemical differences between necrotic and vital glioblastoma as revealed by Raman spectroscopy are in accordance with these results and add information as to the histologic origin of these differences. In spectra derived from necrotic parts of glioblastoma, relative higher carotenoid signal contributions were also observed, consistent with previous Raman studies, in which carotenoids were observed in high-grade gliomas but not in normal brain tissue (Mizuno et al, 1994). The current results indicate that carotenoids are mainly present in the necrotic regions of the tumor. Furthermore, an intense band that was attributed to calcification was observed in Raman spectra from necrotic parts of glioblastoma and seems useful in the identification of necrosis within glioblastoma. High levels of glycogen in glioma were reported in a number of studies (Galarraga et al, 1986; Keller et al, 1981; Ross et al, 1988). The presence of polysaccharides in human glioma tissue was also described by a previous Raman spectroscopic study (Mizuno et al, 1994).

Raman spectroscopy can be applied in vivo using special fiber optic probes optimized for the size and location of the actual measurement volume of the tissue (Puppels, 1999; Puppels et al, 1998, 2001; Shim et al, 1999). Based on the results presented here and these technologic advances, we believe that Raman spectroscopy holds promise for real-time guidance of 

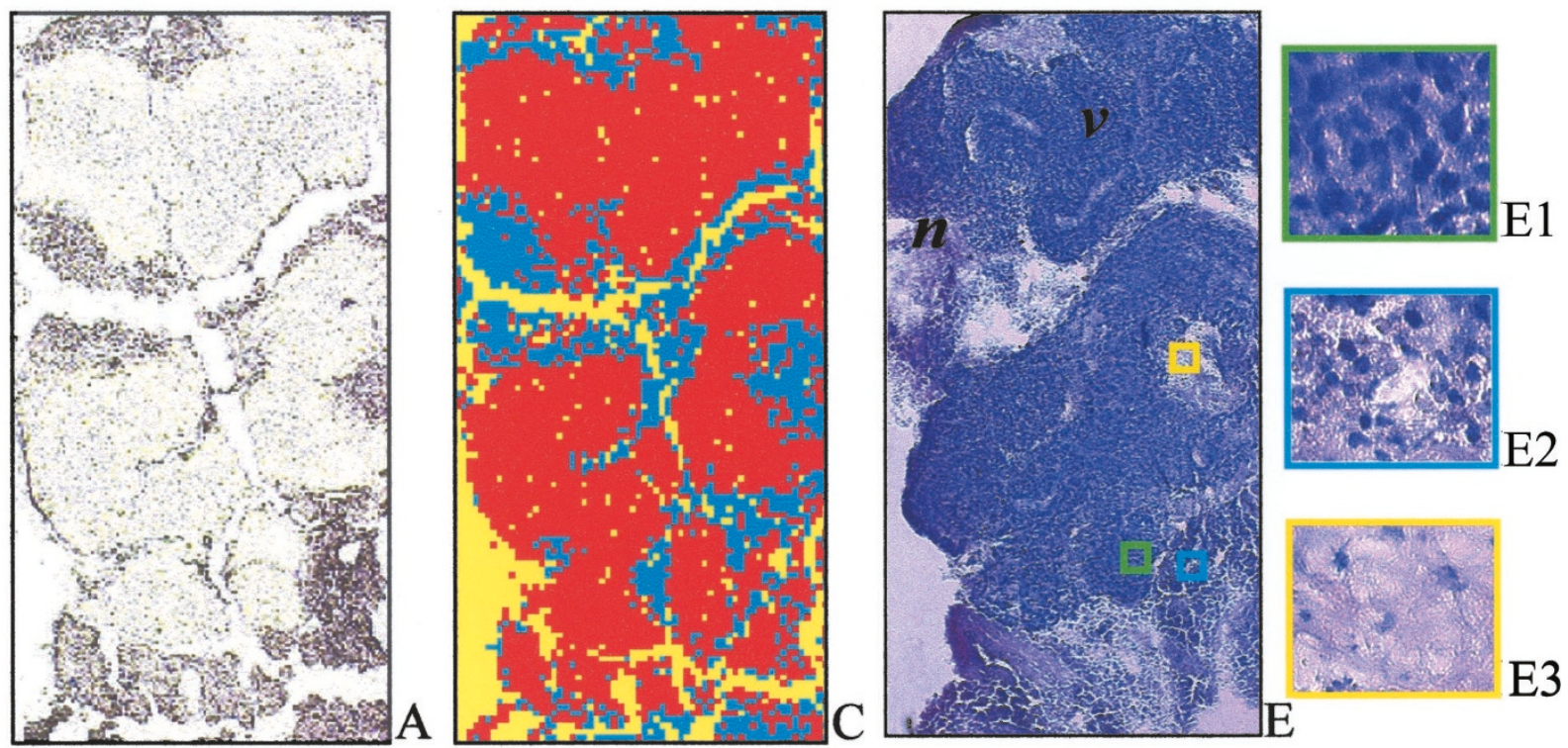

(Size: $1280 \times 2420 \mu \mathrm{m}$ )
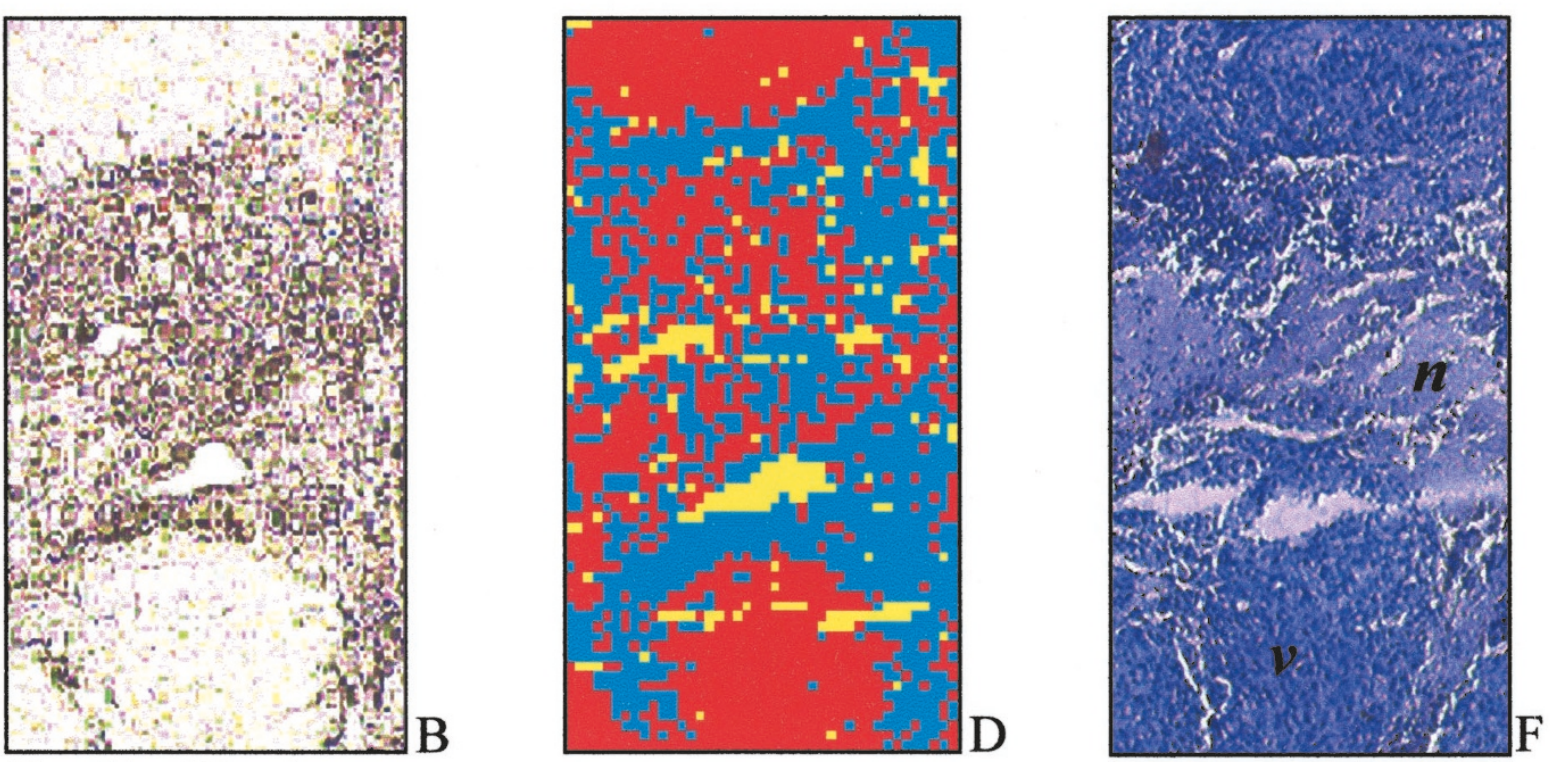

(Size: $504 \times 888 \mu \mathrm{m}$ )

\section{Figure 5.}

A and B, Photomicrographs (original magnification, $\times 5)$ of unstained $(25 \mu \mathrm{m}$ thick) human glioblastoma cryosections before Raman spectroscopic mapping. $C$ and $D$, linear discriminant analysis (LDA) model prediction maps. The spectra obtained from each pixel were used as input for the vital versus necrosis prediction model. Red: vital; blue: necrosis. E and F, Photomicrographs (original magnification, $\times 5$ ) of the same frozen sections after HE staining for histologic evaluation following Raman measurement (vital designated with $v$ and necrotic with $n$ ). E1 to E3: $\times 40$ magnification of details from $5 E$ (frame colors are corresponding), illustrating the changes of tissue structure from vital tumor (E1) to complete necrosis (E3).

brain biopsy, for which thin fiber optic catheters would need to be built into the biopsy needle (Bohorfoush, 1996). The same approach may potentially be of use to distinguish between areas of radiation necrosis and tumor in patients undergoing radiation therapy. Other applications for Raman guided biopsy procedures that can be envisioned include guided biopsy during endoscopy of patients with Barrett's esophagus to better target potential areas of dysplasia (Bakker Schut et al, 2000) and guided fine needle aspiration of suspected breast malignancies.

\section{Materials and Methods}

\section{Patient Samples}

The study was approved by the Medical Ethics Review Board of the University Hospital Rotterdam "Dijkzigt." Informed consent was obtained from each patient. 


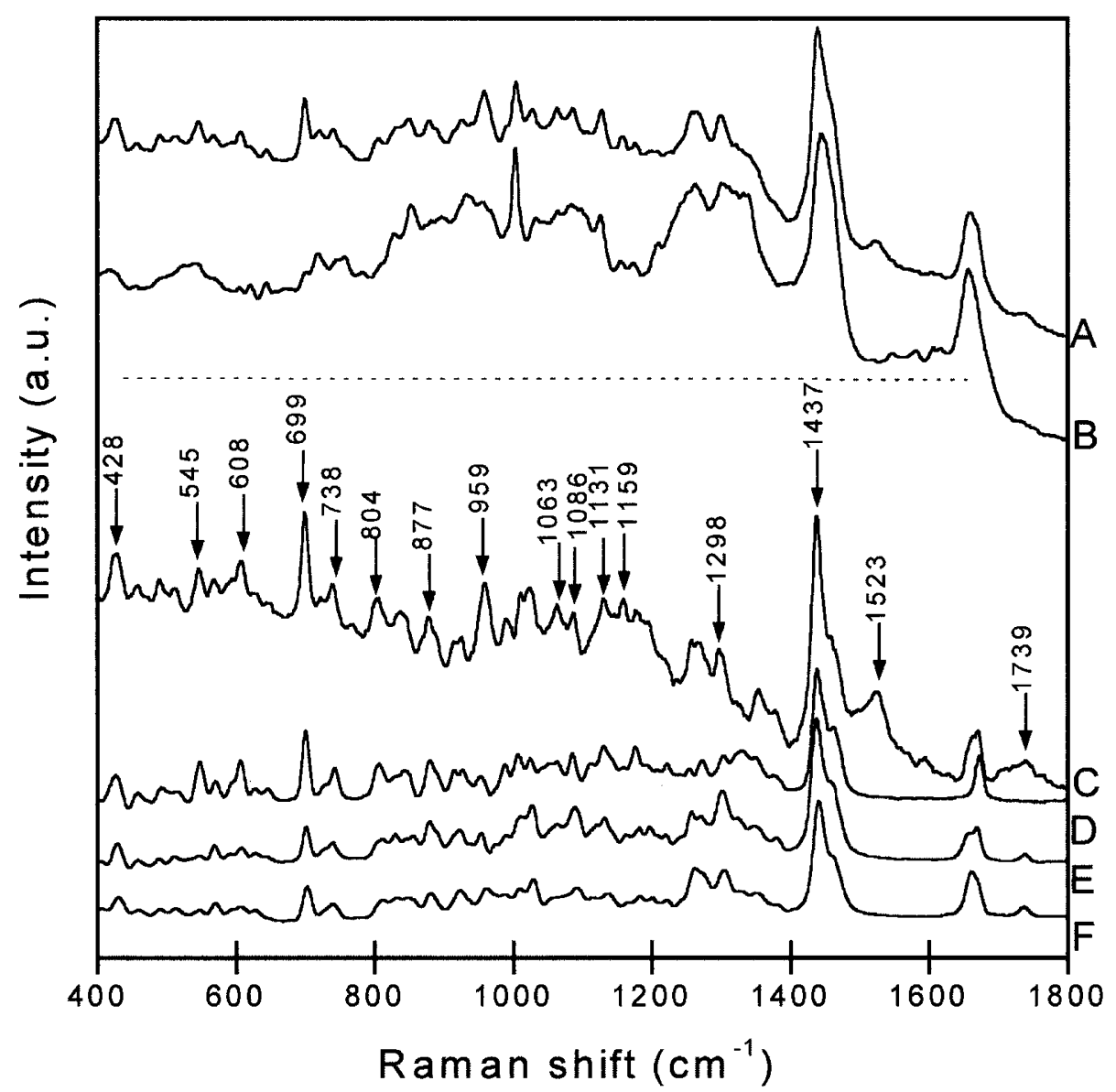

Figure 6.

Averaged Raman spectra of LDA model set, collected from necrotic (A) and vital glioblastoma parts (B). The difference spectrum (necrotic minus vital) shown in C (intensity multiplied by a factor 2) is compared with the Raman spectra of cholesterol (D), cholesterol oleate (E), and cholesterol linoleate (F). a.u. $=$ arbitrary units.

\section{Sample Handling and Sample Preparation}

Tissue specimens originated from resection material or from biopsy specimens obtained during neurosurgical procedures at the Neurosurgery Department of University Hospital Rotterdam "Dijkzigt." After excision, tissue samples were snap-frozen by immersion in liquid nitrogen and stored at $-80^{\circ} \mathrm{C}$ until further use. For Raman experiments, these frozen samples were cut into $25-\mu \mathrm{m}$-thick sections using a cryotome and placed onto calcium fluoride microscope slides and allowed to dry in air. The unfixed tissue sections were used without further treatment. During cryotoming, $5-\mu \mathrm{m}$-thick adjacent sections were also prepared. These thinner sections were stained with $\mathrm{HE}$ and histopathologically evaluated to identify regions of vital tissue and regions of necrosis according to the World Health Organization criteria (Kleihues, 2000). Bright-field images of the unstained tissue sections revealed some heterogeneity in tissue structure, which could be linked to the structural heterogeneity observed in the adjacent stained sections. This assessment was used to select regions in the tissue sections, mostly containing both vital glioblastoma tissue and necrosis for Raman mapping. After Raman measurements, the $25-\mu \mathrm{m}$ tissue sections were HE stained as well, to provide a direct comparison of the Raman mapping results with the histopathology. In this study, a total of 24 Raman mapping sessions were performed on unstained cryosections of glioblastoma tissue derived from 20 patients.

\section{Reference Spectra}

To obtain reference spectra of cholesterol, cholesterol linoleate, cholesterol oleate, calcium hydroxyapatite, and glycogen, commercially available compounds were used (Sigma-Aldrich chemie, Zwijndrecht, The Netherlands).

\section{Raman Microspectrometer}

Raman spectra of the tissue sections were obtained by a near-infrared multichannel Raman microspectrometer built in house. Briefly, the setup consists of a microscope (DM-RXE; Leica, Cambridge, United 


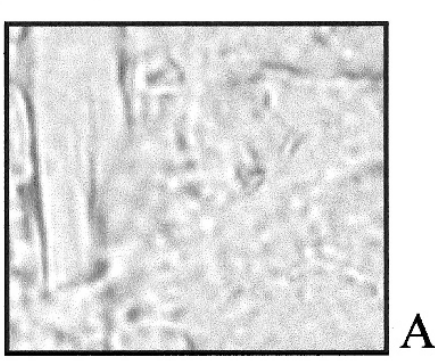

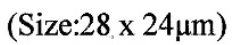

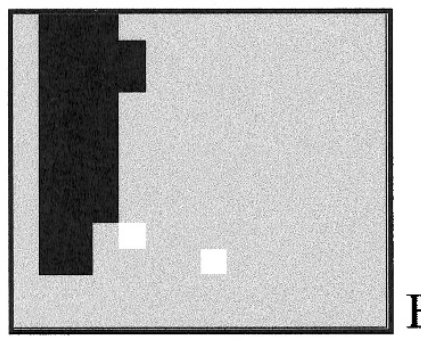

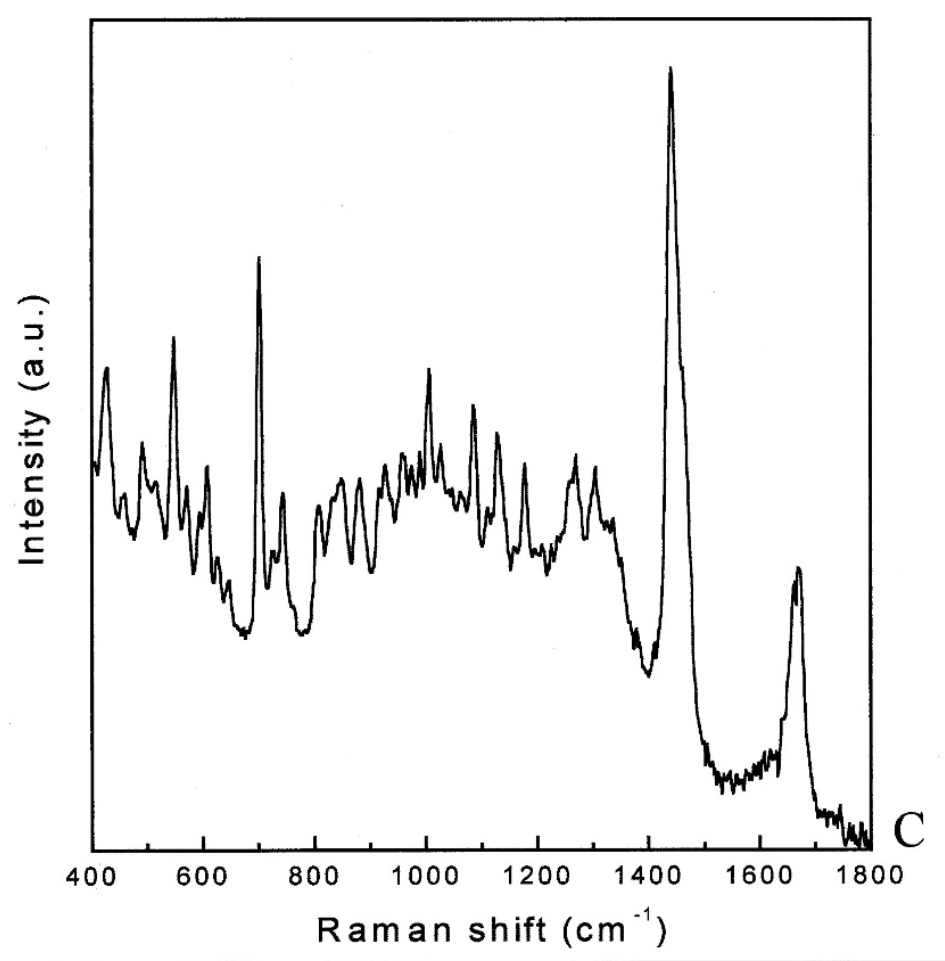

Figure 7.

A, Photomicrograph of unstained frozen section showing a necrotic area of glioblastoma with a microscopic crystal-like inclusion (original magnification, $\times 80$ ). B, Raman-map (upon KCA) of the histologic detail displayed in A (scanning step size $2 \mu \mathrm{m}$ ). C, Raman spectrum (average) of the crystal-like inclusion (predominantly cholesterol; see Fig. 3E).

Kingdom) coupled to a Raman spectrometer (System 100; Renishaw, Wotton under Edge, United Kingdom). Laser light of $847 \mathrm{~nm}$ is focused on the sample by a $\times 80$ NIR optimized objective (Olympus, Tokyo, Japan). The objective also collects light that is scattered by the sample, which is then analyzed by the spectrometer. Raman signal was collected in the spectral interval from 400 to $1800 \mathrm{~cm}^{-1}$, with a spectral resolution of $8 \mathrm{~cm}^{-1}$. This system has recently been described in detail (van de Poll et al, 2001).

Unstained cryosections $(25 \mu \mathrm{m})$ of glioblastoma tissue were placed on an xyz-motorized, computercontrolled sample stage (Leica DM STC), which enabled automatic scanning of the sample. The laser light was focused below the surface of the tissue at such a depth that the signal intensity was maximized. The area to be scanned and the scanning step size were chosen, therefore dividing up the area of interest into small square areas (here termed Raman pixel). Spectra were obtained consecutively from the tissue in each of these Raman pixels, the size of which varied between 0.25 and $400 \mu \mathrm{m}^{2}$, for different measurements. The $\times 80$ microscope objective focused the laser light to a spot of less than $1 \mu \mathrm{m}^{2}$. Therefore, to obtain a spectrum that is representative for the tissue in a Raman pixel, the area of the Raman pixel was scanned during each spectral measurement. Acquisition of Raman spectra and microscopic stage movement was controlled by the WiRE 1.2 software (Renishaw) running under Grams/32 Spectral Notebase
Software (Galactic Industries Corporation, Salem, Massachusetts). Raman mapping software was implemented in Array Basic (the internal software platform of Grams) and controlled the Leica microscope unit and the microscope stage.

Tissue samples were excited with 90 to $110 \mathrm{~mW}$ of laser power during Raman experiments. Spectra were usually obtained using 10 seconds of signal collection time per Raman pixel.

\section{Data Analysis}

The Raman data were analyzed with software developed in house that operates in the Matlab environment (The MathWorks, Inc., Natick, Massachusetts) using the multivariate statistical analysis toolbox PLStoolbox 2.0.0c (Eigenvector Research, Inc., Manson, Washington).

\section{Pretreatment of Spectra}

After acquisition, the spectra were first calibrated using Raman calibration standards as described earlier (Wolthuis et al, 1999). The reference spectrum of a tungsten-band lamp of known temperature was used to correct for the wavelength-dependent signal detection efficiency of the Raman setup. Spectral pretreatment also involved the subtraction of interfering background Raman signal originating in the optical 


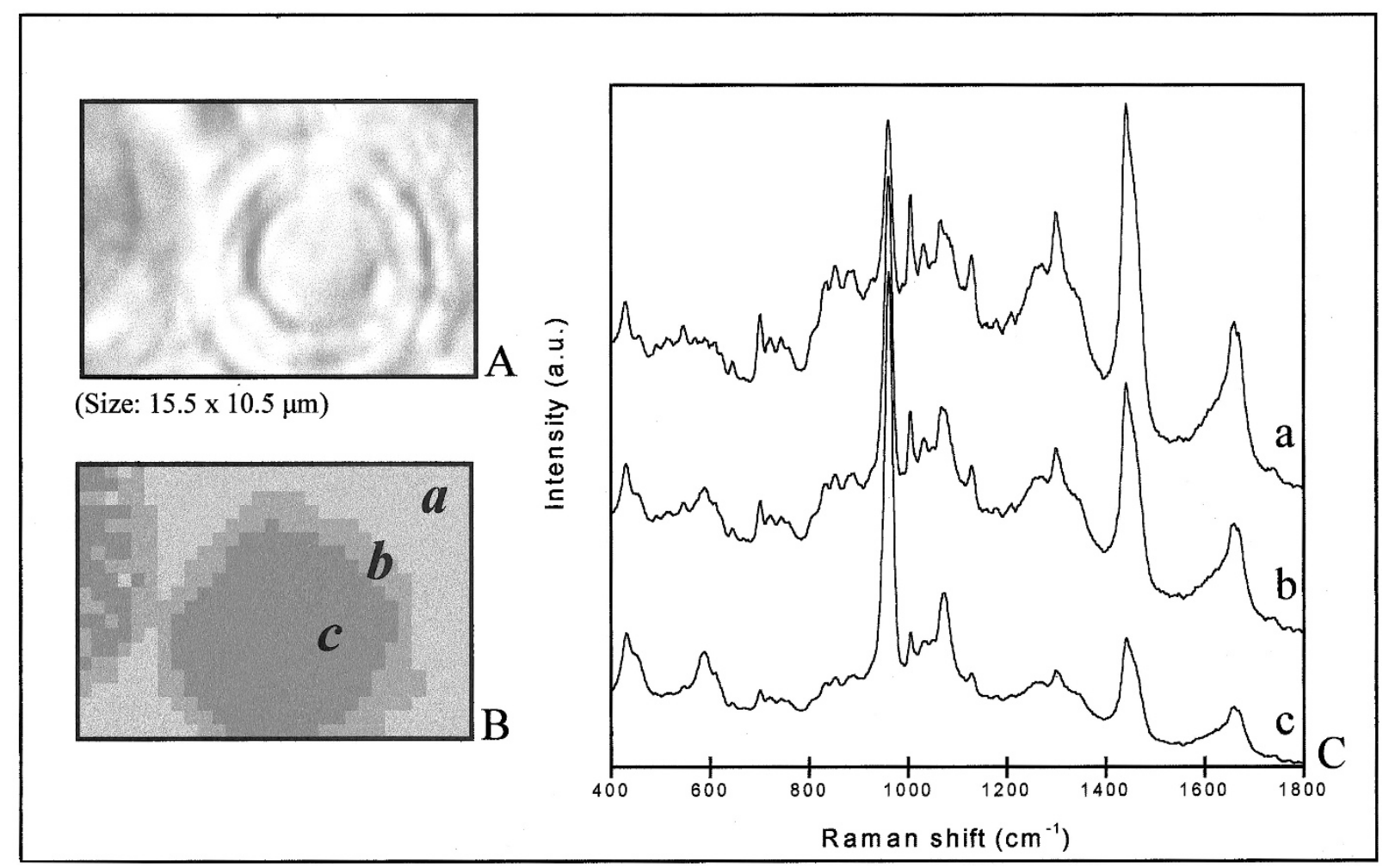

Figure 8.

A, Bright-field image of calcification deposit in a necrotic glioblastoma region (original magnification, $\times 80$ ). B, Raman map, based on the KCA with three clusters (scanning step size $0.5 \mu \mathrm{m}$ ). C, Raman spectra (averages) of (a) surrounding necrotic tissue, (b) periphery of calcification, and (c) center of calcification (predominantly calcium hydroxyapatite; see Fig. 3F).

elements in the laser light delivery pathway and the calcium fluoride slide.

\section{Raman Maps}

Raman maps were constructed from the spectral data set using multivariate statistical techniques. To minimize the influence of any slowly varying fluorescence or background scatter in the spectra which is noninformative, the first derivative of the spectra was taken (using the Savitzky-Golay method). The resulting spectra were subsequently scaled so that all the derivative spectra of a map had zero mean and unit standard deviation (autoscaling or standard normal variate scaling) (Wolthuis et al, 1999).

PCA was used to orthogonalize and reduce the number of parameters needed to represent the variance in the spectral data set (Jollife, 1986). Cluster analysis was then used to find groups of spectra that have similar spectral characteristics. PCA scores accounting for $99.9 \%$ of the variance captured served as input for KCA. KCA was performed because it can easily handle large amounts of data as obtained during Raman mapping experiments (Jain and Dubes, 1988). The algorithm was initiated by allowing the user to choose the number of clusters. The criteria used to determine the number of clusters to be included in the analysis were that the final cluster-averaged spectra displayed meaningful spectral differences (ie, above noise level) and that the clusters could be related to histologically distinct areas in the tissue sections (see section below on pseudo-color Raman maps). The initial values for the centers of these clusters were taken randomly from the spectral data set. All spectra in the data set were then compared with these cluster centers and assigned to the center that they most resembled. After assigning all spectra to one of the clusters, the new cluster center was calculated by taking the mean of all the spectra that were assigned to that cluster. This procedure was repeated until a stable solution was reached. The cluster-membership information was plotted as a pseudo-color map by assigning a color to each different cluster.

\section{Raman Maps and Histopathology}

The location of each differently colored area in the pseudo-color Raman maps was compared with the histopathology. Depending on whether different colors corresponded with vital or necrotic regions within an HE-stained section, each cluster was labeled "vital" or "necrotic," irrespective of the Raman spectroscopic results.

\section{Raman Difference Spectra}

Information about differences in biochemical composition of the various structures can be extracted from "positive" difference spectra, which are calculated by scaled subtraction of the cluster averages from each 


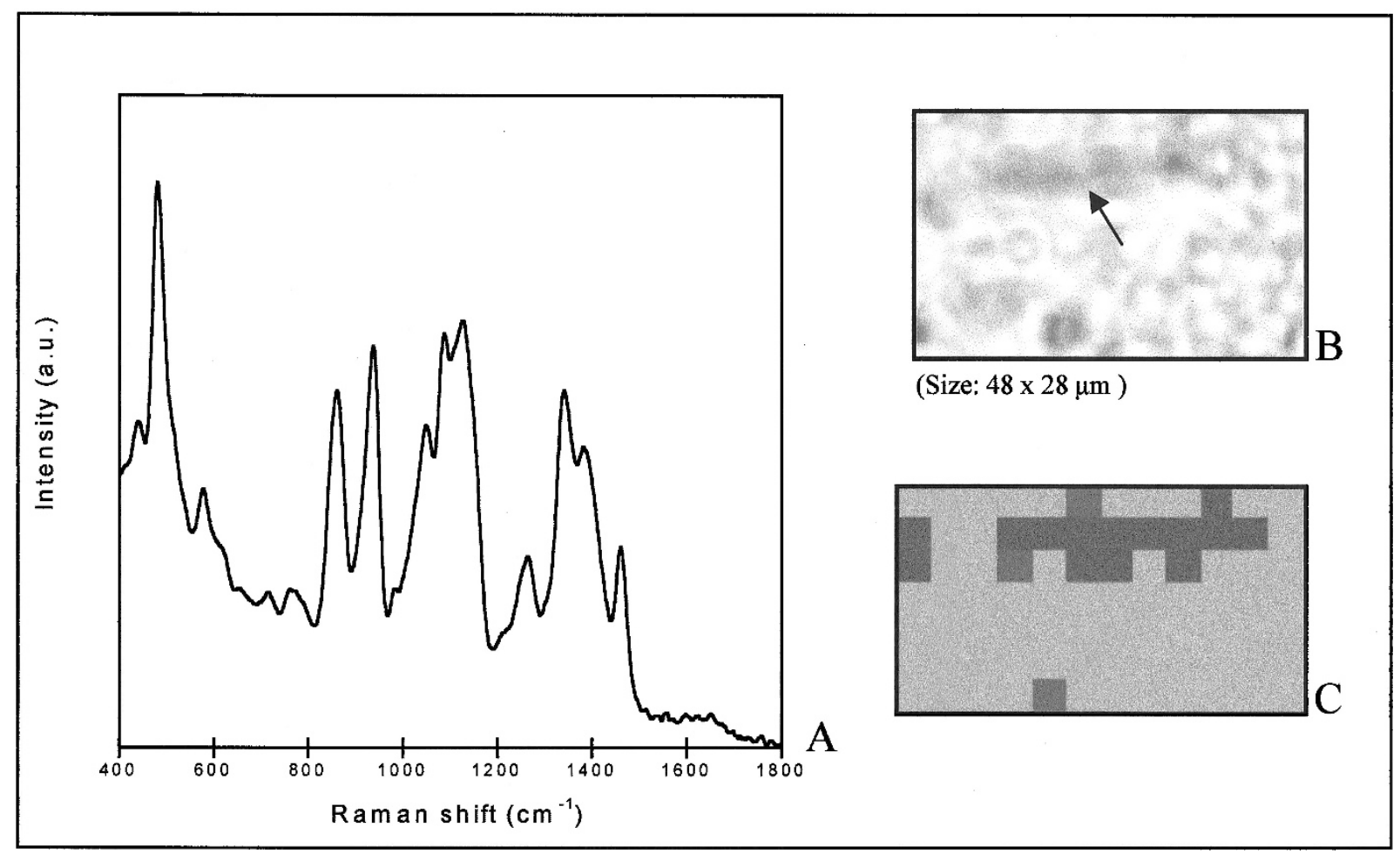

Figure 9.

A, Raman spectrum (average) collected from area shown in B (arrow). This spectrum shows a strong overlap with Raman spectrum of pure glycogen (see Fig. 2E). $\mathrm{B}$, Photomicrograph of unstained cryosection showing histologic detail within a vital glioblastoma region (original magnification, $\times 80$ ). C, Corresponding KCA Raman map (scanning step size $2 \mu \mathrm{m}$ ).

other. In short, for two given spectra, $\mathrm{N}$ and $\mathrm{V}$, a difference spectrum $\mathrm{N}-\mathrm{V}$ is calculated, where $\mathrm{V}$ is scaled in such a way that the difference spectrum does not show negative Raman features. The resulting difference spectrum gives a good impression of which molecular species are present in a relatively higher amount in spectrum $\mathrm{N}$ than in spectrum $\mathrm{V}$.

\section{LDA Modeling}

Based on the histopathologic cluster assignment, an LDA model was built. LDA is a supervised modeling technique that finds the best linear combination of variables to discriminate between the two groups (Tabachnick and Fidell, 1989). For this purpose, a database consisting of cluster-averaged spectra was created. Before averaging, the spectra were first pretreated as described above (Savitzky-Golay differentiation method and autoscaling). Then PCA was performed on this data set to obtain a representation of the spectra in a reduced number of orthogonal variables. To prevent overfitting in the LDA model, the number of PCs used in the model should be at least two times smaller than the number of spectra in the smallest model group. Therefore only those PCs that show high significance in discriminating necrosis from vital glioma were individually selected by using the two-sided $t$ test.

The internal consistency of the LDA model data set was evaluated with leave-one-out testing. In this test, the classification of each single cluster average is predicted using an LDA model that is built on all model cluster averages minus the cluster average to be predicted (Stone, 1974). The prediction accuracy of the LDA model was tested by predicting whether cluster averages from independent samples (ie, not used for the model database) originated from vital or necrotic tumor parts.

\section{References}

Bakker Schut TC, Witjes M, Sterenborg M, Speelman O, Roodenburg J, Marple E, Bruining H, and Puppels GJ (2000). In vivo detection of dysplastic tissue by Raman spectroscopy. Anal Chem 72:6010-6018.

Barba I, Cabañas ME, and Arús C (1999). The relationship between nuclear magnetic resonance-visible lipids, lipid droplets, and cell proliferation in cultured C6 cells. Cancer Res 59:1861-1868.

Bohorfoush AG (1996). Tissue spectroscopy for gastrointestinal diseases. Endoscopy 28:372-380.

Boustany NN, Crawford JM, Manoharan R, Dasari RR, and Feld MS (1999). Analysis of nucleotides and aromatic amino acids in normal and neoplastic colon mucosa by ultraviolet resonance Raman spectroscopy. Lab Invest 79:1201-1214.

Bullard DE, Osborne D, Burger PC, and Nashold BS (1986). Further experience utilizing the Gildenberg technique for computed tomography-guided stereotactic biopsies. Neurosurgery 19:386-391.

Buschman R, Marple ET, Wach ML, Bennett B, Bakker Schut TC, Bruining HA, Bruschke AV, van der Laarse $A$, and 
Puppels GP (2000). In vivo determination of the molecular composition of artery wall by intravascular Raman spectroscopy. Anal Chem 72:3771-3775.

Campanella R (1992). Membrane lipids modifications in human gliomas of different degree of malignancy. J Neurosurg Sci 36:11-25.

Dowling C, Bollen AW, Noworolski SM, McDermott MW, Barbaro NM, Day MR, Henry RG, Chang SM, Dillon WP, Nelson SJ, and Vigneron DB (2001). Preoperative proton MR spectroscopic imaging of brain tumors: Correlation with histopathologic analysis of resection specimens. AJNR Am J Neuroradiol 22:604-612.

Field M, Witham TF, Flickinger JC, Kondziolka D, and Lunsford LD (2001). Comprehensive assessment of hemorrhage risks and outcomes after stereotactic brain biopsy. J Neurosurg 94:545-551.

Fountas KN, Kapsalaki EZ, Gotsis SD, Kapsalakis JZ, Smisson HF, Johnston KW, Robinson JS, and Papadakis N (2000). In vivo proton magnetic resonance spectroscopy of brain tumor. Stereotact Funct Neurosurg 74:83-94.

Frank CJ, McCreery RL, and Redd DC (1995). Raman spectroscopy of normal and diseased human breast tissues. Anal Chem 67:777-783.

Galarraga J, Loreck DJ, Graham JF, DeLaPaz RL, Smith BH, Hallgren D, and Cummins CJ (1986). Glucose metabolism in human gliomas: Correspondence of in situ and in vitro metabolic rates and altered energy metabolism. Metab Brain Dis 1:279-291.

Glantz MJ, Burger P, Herndon J, Friedman A, Cairncross J, Vick N, and Schold SC (1991). Influence of the type of surgery on the histologic diagnosis in patients with anaplastic gliomas. Neurology 41:1741-1744.

Gopel K, Grassi E, Paoletti P, and Usardi M (1963). Lipid composition of human intracranial tumors: A biochemical study. Acta Neurochir (Wien) 11:333.

Hall WA, Lui H, Truwit CL, and Martin AJ (1999). Comparison of stereotactic brain biopsy to interventional magneticresonance-imaging-guided brain biopsy. Stereotact Funct Neurosurg 73:148-153.

Hall WA, Martin AJ, Lui H, and Truwit CL (2001). Improving diagnostic yield in brain biopsy: Coupling spectroscopic targeting with real-time needle placement. J Magn Reson Imaging 13:12-15.

Hanlon EB, Manorahan R, Koo TW, Shafer KE, Motz JT, Fitzmaurice M, Kramer LR, Itzakan I, Dasari RR, and Feld MS (2000). Prospects for in vivo Raman spectroscopy. Phys Med Biol 45:R1-R59.

Hildebrand J, Dewitte O, Dietrich PY, and de Tribolet N (1997). Management of malignant brain tumors. Eur Neurol 38:238-253.

Hirakawa T, Maruyama K, Kohl NE, Kodama T, and Ruley EH (1991). Massive accumulation of neutral lipids in cells conditionally transformed by an activated $\mathrm{H}$-ras oncogene. Oncogene 6:289-295.

Jain AK and Dubes RC (1988). Algorithms for clustering data. Engelwood Cliffs: Prentice Hall.

Jollife IT (1986). Principal component analysis. New York: Springer-Verlag.

Keller K, Lange K, and Noske W (1981). D-Glucose transport in cultured cells of neural origin: The membrane as possible control point of glucose utilization. J Neurochem 36:10121017.

Kleihues $P$ (2000). Pathology and genetics of tumours of the nervous system. In: Kleihues $P$ and Cavenee WK, editors. World Health Organization Classification of Tumors. Lyon: IARC Press.

Kleihues P, Volk B, Anagnostopoulos J, and Kiessling M (1984). Morphologic evaluation of stereotactic brain tumor biopsies. Acta Neurochir 33:171-181.

Kros JM (1997). Laboratory diagnosis of brain tumors. In: Vecht ChJ, editor. Handbook of clinical neurology (NeuroOncology, part I), vol. 23. Amsterdam: Elsevier Science B.V., 217-233.

Kuesel AC, Briere KM, Halliday W, Sutherland GR, Donnelly SM, and Smith IC (1996). Mobile lipid accumulation in necrotic tissue of high grade astrocytomas. Anticancer Res 16:1845-1849.

Kuesel AC, Donnelly SM, Halliday W, Sutherland GR, and Smith IC (1994a). Mobile lipids and metabolic heterogeneity of brain tumors as detectable by ex vivo $1 \mathrm{H}$ MR spectroscopy. NMR Biomed 7:172-180.

Kuesel AC, Sutherland GR, Halliday W, and Smith IC (1994b). $1 \mathrm{H}$ MRS of high grade astrocytomas: Mobile lipid accumulation in necrotic tissue. NMR Biomed 7:149-155.

Kurhanewicz J, Vigneron DB, and Nelson SJ (2000). Threedimensional magnetic resonance spectroscopic imaging of brain and prostate cancer. Neoplasia 2:166-189.

Mahadevan-Jansen A, Mitchell MF, Ramanujam N, Malpica A, Thomasen S, Utzinger U, and Richards-Kortum R (1998a). Near-infrared Raman spectroscopy for in vitro detection of cervical precancers. Photochem Photobiol 68:123-132.

Mahadevan-Jansen A, Mitchell MF, Ramanujam N, Malpica A, Utzinger U, and Richards-Kortum R (1998b). Development of a fiber optic probe to measure NIR Raman spectra of cervical tissue in vivo. Photochem Photobiol 68:427-431.

Mahadevan-Jansen A and Richards-Kortum R (1996). Raman spectroscopy for the detection of cancers and precancers. J Biomed Opt 1:31-70.

Manoharan R, Schafer K, Perelman L, Wu J, Chen K, Deinum G, Fitzmaurice M, Myles J, Crowe J, Dasari RR, and Feld MS (1998). Raman spectroscopy and fluorescence photon migration for breast cancer diagnosis imaging. Photochem Photobiol 67:15-22.

Manoharan R, Wang Y, Dasari RR, Singer SS, Rava RP, and Feld MS (1994). Ultraviolet resonance Raman spectroscopy for detection of colon cancer. Lasers Life Sci 6:1-11.

Manoharan R, Wang Y, and Feld MS (1996). Histochemical analysis of biological tissues using Raman spectroscopy. Spectrochimica Acta Part A 52:215-249.

Mizuno A, Hayashi T, Tashibu K, Maraishi S, Kawauchi K, and Ozaki Y (1992). Near-infrared FT-Raman spectra of the rat brain tissues. Neurosci Lett 141:47-52.

Mizuno A, Kitajima H, Kawauchi K, Muraishi S, and Ozaki Y (1994). Near-infrared transform Raman spectroscopic study of human brain tissues and tumors. J Raman Spect 25:2529 .

Negendank WG, Sauter R, Brown TR, Evelhoch JL, Falini A, Gotsis ED, Heerschap A, Kamada K, Lee BC, Mengeot MM, Moser E, Padavic-Shaller KA, Sanders JA, Spraggins TA, Stillman AE, Terwey B, Vogl TJ, Wicklow K, and Zimmerman 
RA (1996). Proton magnetic resonance spectroscopy in patients with glial tumors: A multicenter study. J Neurosurg 84:449-458.

Nelson SJ, Vigneron DB, and Dillon WP (1999). Serial evaluation of patients with brain tumors using volume MRI and 3D ${ }^{1} \mathrm{H}$ MRSI. NMR Biomed 12:123-138.

Nygren C, von Holst H, Månsson J-E, and Fredman P (1997). Increased levels of cholesterol esters in glioma tissue and surrounding areas of human brain. Br J Neurosurg 11:216220

Ong CW, Shen ZX, He Y, Lee T, and Tang SH (1998). Raman microspectroscopy of the brain tissues in the substantia nigra and MPTP-induced Parkinson's disease. J Raman Spectrosc 30:91-96.

Paulus W and Peiffer J (1989). Intratumoral histologic heterogeneity of gliomas. Cancer 64:442-447.

Pirzkall A, McKnight TR, Graves EE, Carol MP, Sneed PK, Wara WW, Nelson SJ, Verhey LJ, and Larson DA (2001). MR-spectroscopy guided target delineation for high-grade gliomas. Int J Radiation Oncology Biol Phys 50:915-928.

Puppels GJ (1999). Confocal Raman spectroscopy. In: Mason WT, editor. Fluorescent and luminescent probes for biological activity. London: Academic Press, 377-406.

Puppels GJ, Bakker Schut TC, Caspers PJ, Wolthuis R, van Aken M, van der Laarse, Bruining HA, Buschman HPJ, Shim MG, and Wilson MC (2001). In vivo Raman spectroscopy. In: Lewis IR and Edwards HGM, editors. New York: Marcel Dekker, 549-574.

Puppels GJ, van Aken T, Wolthuis R, Caspers PJ, Bakker Schut TC, and Bruining HA (1998). Infrared spectroscopy: New tool in medicine. In: Mantasch $\mathrm{HH}$, Jackson $\mathrm{M}$, and Katzir A, editors. SPIE conference proceedings, vol. 3257. Washington: The International Society for Optical Engineering, 78-83.

Rémy C, Fouilhé N, Barba I, Sam-Laï E, Lahrech H, Cucurella M-G, Izquierdo M, Moreno A, Ziegler A, Massarelli R, Décorps M, and Arús C (1997). Evidence that mobile lipids detected in rat brain glioma by ${ }^{1} \mathrm{H}$ nuclear magnetic resonance correspond to lipid droplets. Cancer Res 57:404-414.

Ross BD, Higgins RJ, Boggan JE, Willis JA, Knittel B, and Unger SW (1988). Carbohydrate metabolism of the rat C6 glioma: $\mathrm{An}$ in vivo $13 \mathrm{C}$ and in vitro $1 \mathrm{H}$ magnetic resonance spectroscopy study. NMR Biomed 1:20-26.

Sawin PD, Hitchon PW, Follet KA, and Torner JC (1998). Computed imaging-assisted stereotactic brain biopsy: A risk analysis of 225 consecutive cases. Surg Neurol 49:640-649.
Scerrati M and Rossi GF (1984). The reliability of stereotactic biopsy. Acta Neurochir 33:201-205.

Shim MG, Song LM, Marcon NE, and Wilson BC (2000). In vivo near-infrared Raman spectroscopy: Demonstration of feasibility during clinical gastrointestinal endoscopy. Photochem Photobiol 72:3771-3775.

Shim MG, Wilson BC, Marple E, and Wach M (1999). Study of fiber-optic probes for in vivo medical Raman spectroscopy. Appl Spectrosc 53:619-627.

Stone M (1974). Cross-validatory choice and assessment of statistical assessment of statistical predictions (with discussion). J Royal Stat Soc B 36:111-147.

Stone N, Stavroulaki P, Kendall C, Birchall M, and Barr H (2000). Raman spectroscopy for early detection of laryngeal malignancy: Preliminary results. Laryngoscope 110:17561763.

Tabachnick B and Fidell L (1989). Using multivariate statistics, 3rd ed. New York: Harper Collins Publishers.

Tu AT (1982). Basic concept and elementary theory: Raman spectroscopy in biology. New York: John Wiley \& Sons.

van de Poll SWE, Romer TJ, Volger OL, Delsing DJM, Bakker Schut TC, Princen HMG, Jukema JW, Havekes L, van der Laarse A, and Puppels GJ (2001). Raman spectroscopic evaluation of the effects of diet and lipid-lowering therapy on atherosclerotic plaque development in mice. Arterioscler Thromb Vasc Biol 21:1630-1635.

Vigneron D, Bollen A, McDermott M, Wald I, Day M, MoyherNoworolski S, Henry R, Chang S, Berger M, Dillon W, and Nelson S (2001). Three-dimensional magnetic resonance spectroscopic imaging of histologically confirmed brain tumors. Magn Reson Imaging 19:89-101.

Wolthuis R, Bakker Schut TC, Caspers PJ, Buschman HP, Römer TJ, Bruining HA, and Puppels GJ (1999). Raman spectroscopy methods for in vitro and in vivo tissue characterization. In: Mason WT, editor. Fluorescent and luminescent probes for biological activity. San Diego: Academic Press, 433-455.

Wolthuis $\mathrm{R}$, van Aken M, Fountas K, Robinson JS, Bruining HA, and Puppels GJ (2001). Determination of water concentration in brain tissue by Raman spectroscopy. Anal Chem 73:3915-3920. 